\title{
ИСТОРИЯ ВЫПУСКА КЯХТИНСКИХ БОН В 1918 ГОДУ (по материалам следственного дела комиссара финансов А.И. Малафеева)
}

В статье, на основе неопубликованных ранее данных из фондов Национального архива Республики Бурятия (НАРБ), анализируется проведение локальной уездной денежной эмиссии в период Гражданской войны (1918 г.) - изготовление и выпуск в обращение бон Кяхтинского отделения Госбанка при активном участии советских органов власти. Осуществлен обзор историографии данной проблемы, выявлены спорные вопросы, предпринята попытка преодоления некоторых противоречий в существующей отечественной историографии.

Ключевые слова: гражданская война; советская власть; Кяхта; Троицкосавск; денежное обращение; денежные суррогаты; бонистика.

P.V. KURGUZOV

\section{HISTORY OF THE RELEASE OF KYAKHTIN BONS IN 1918 (according to the materials of the investigation file of the Commissioner of Finance A.I. Malafeev)}

In the article, on the basis of previously unpublished data from the funds of the National Archive of the Republic of Buryatia (NARB), a local county issue of money during the Civil War (1918) is analyzed - production and issuance of Bon of the Kyakhta branch of the State Bank with the active participation of Soviet authorities. A review of the historiography of this problem has been carried out, controversial issues have been identified, an attempt has been made to overcome some of the contradictions in the existing Russian historiography.

Keywords: civil war; soviet authority; Kyahta; Troitskosavsk; money turnover; monetary surrogates; bonistics.

Первая мировая война и две русские революции в начале $\mathrm{XX}$ в. коренным образом изменили фринансовую систему Российской империи и будущего Советского государства. Достаточно устойчивая эмиссионная политика государства, сменилась полным развалом государственных финансов и экономики. Бесконтрольное печатание денег привело к тому, что в 1917 г. масса денег в обращении превысила объемы 1914 г. в 10 раз. Индекс потребительских цен в розничном обороте превысил аналогичные довоенные показатели в 13 раз. 
Еще более плачевная ситуация сложилась в Сибири и на Дальнем Востоке России. Начиная, со второй половины 1917 г., помимо инфляции, острая нехватка денежной наличности стала настоящей угрозой экономическому существованию сибирских регионов, предрекающей финансовый коллапс. Без фринансовых подкреплений из центра местные экономические центры рисковали остаться без полноценно работающего государственного и муниципального механизма управления, угрожающим параличом транспорта, связи и других важных секторов экономики.

Не обошла эта беда и территории небольших городков Сибири, таких как Троицкосавск, с ее слободами Кяхтой и Усть-Кяхтой, и всеми ее населенными пунктами, входящими в одноименный уезд. Ситуация усложнялась еще и приграничным положением Троицкосавска, с его достаточно развитыми товарно-денежными взаимоотношениями с контрагентами из Монголии и Китая, основанными на финансовых сделках под твердое золотое обеспечение.

Все это и обеспечило появление летом 1918 г. в Троицкосавске собственных денег, так называемых «малафреевок», или кяхтинских бон.

В последующие годы, данные события получили достаточно подробное освещение в советской историографии. Первым на денежные мероприятия властей Кяхты обратил внимание в 1924 г. известный исследователь денежного обращения в Сибири и на Дальнем Востоке в период гражданской войны А.И. Погребецкий [3].

В 1930 г. на страницах журнала «Советский коллекционер» более обстоятельно, с привлечением архивных документов эту историю рассмотрел М.С. Сафонов [4]. На основе документов из фонда Верхнеудинского казначейства он впервые скрупулезно и последовательно рассказал об истории выпуска кяхтинских бон, указал количество выпущенных денежных знаков и пр. Надо отметить, что опубликованные им документы Центрального архивного управления Бурят-Монгольской АССР, а ныне Национального архива Республики Бурятия в настоящее время не сохранились. Изменились не только номера фондов, дел и описей, но и, к сожалению, при проверке в текущем году выяснилось, что эти документы из фондов Казначейства исчезли и поэтому приведенные М.C. Сафоновым источники являются ныне достаточно уникальными документальными свидетельствами той эпохи. В постсоветское время все это объединил и добавил данными из Центрального управления Государственного банка Министерства финансов правительства А.В. Колчака российский ученый из Томска Д.И. Петин [2].

Тем не менее, нами обнаружены еще несколько документов того периода, дополняющих сведения об истории возникновения кяхтинских бон. Это документы Троицкосавского отделения Народного (Государственного) банка за 1918 г., где сохранились экземпляры чистых бланков 
указанных выше бон и копии актов об их выпуске [1, ф. 222, оп. 2, д. 59]. Кроме того, были найдены в фонде 2-го (белогвардейского) Военного района (г. Верхнеудинск), следственное дело уездного комиссара фринансов А.И. Малафеева, подпись которого и стояла на местных денежных знаках, вместе с временным управляющим банка В.И. Ермоленко [1, фр. 1547, оп. 2, д. 3]. Эти документы существенно уточняют и конкретизируют наиболее спорные моменты в истории кяхтинских бон, и дают подлинную картину осуществления этой фринансовой операции сто лет тому назад в далеком 1918 г.

Как уже упоминалось выше, к началу 1918 г. в Троицкосавском уезде ввиду отсутствия денежной наличности сложилась очень непростая ситуация. Задержка финансовой помощи из Петрограда в виде доставки мелкой монеты и банкнот была порождена, по мнению большинства исследователей, саботажем центра и нарушенными транспортными сообщениями. Наиболее остро эта проблема проявилась весной 1918 г., после выступления чехословацкого корпуса. В этот период восточные регионы, находящиеся под властью большевистской Центросибири, оказались фрактически отрезаны от центра, и ситуация со снабжением ухудшалась с каждым днем. Особенным дефицитом стали денежные знаки с мелкими номиналами, полностью исчезли копейки. Вся эти объективные трудности совпали со сменой власти в Троицкосавске.

В марте 1918 г., усилиями вернувшихся в город фронтовиков, многие из которых уже успели поучаствовать в декабрьских событиях 1917 г. в Иркутске на стороне красногвардейских отрядов, был сформирован большевистский Совет. Возглавил его выходец из соседнего Селенгинска прапорщик-артиллерист, бывший военный комендант г. Иркутска, активный участник подавления юнкерского восстания Б.Н. Мельников. Заместителями его стали К.А. Масков и А.И. Малафеев. Вскоре после создания Байкальского фронта Б.Н. Мельников был отозван его командующим П.К. Голиковым на должность адъютанта и новым председателем Троицкосавского совета стал К.А. Масков, а его первым заместителем комиссар финансов и в дальнейшем промышленности Андрей Ильич Малафеев.

В июне 1918 г на видных местах города Троицкосавск и его двух слободах появились объявление, которое стоит воспроизвести полностью.

«Объявление.

Согласно постановления Совета Народных Комиссаров Троицкосавского Уезда от 19 июня нового стиля 1918 г. Кяхтинское отделение Народного Банка доводит до сведения граждан, что в виду ограниченного запаса, в местном отделении Народного Банка денежных знаков старого образца мелких достоинств, с 20-го сего июня нового стиля временно, впредь до получения подкрепления из центра упомянутыми денежными знаками прекращается размен на старые кредитные билеты мелких достоинств причем разных крупных купюр, а на казначейские знаки сорока и двадцати 
рублевого достоинства будет производится беспрепятственно и в неограниченном размере. Для удовлетворения нужд населения в мелких денежных знаках в ближайшем будущем местным отделением Народного Банка будут выпущены боны с правом хождения наравне со всеми кредитными билетами. О выпуске и образцах предполагаемых бон население будет своевременно поставлено в известность. Такие меры проведены уже во многих городах Сибири и вызваны они исключительно временным перерывом сообщения с центром. Одновременно с настоящим объявлением Совет Народных Комиссаров Троицкосавского Уезда просит население относиться к этой мере как можно спокойнее и не верить распускаемым злостным слухам о якобы предстоящем аннулировании всех денежных знаков нового образца, ибо слухи эти не имеют под собой почвы.

Комиссар фринансов А. Малафеев.

Исполняющий обязанности управляющего Кяхтинским Отделением Народного Банка В. Ермоленко» [1, ф. 1547, оп. 2, д. 3, л. 57].

Личность А.И. Малафеева в силу специфики занимаемой им должности и дальнейшего развития событий, несомненно, заслуживает особого внимания.

Однако, биографические данные, этапы его жизненного пути, эволюция его политических взглядов недостаточно изучены в исторической литературе. Только в работе В.Т. Кравцова, «Кяхта революционная», изданной в Улан-Удэ в 1977 г., говорится, что после падения Советской власти в Кяхте осенью 1918 г. он пропал без вести.

В монографии Е. М. Даревской, «Сибирь и Монголия», (Иркутск, 1994 г.), приводятся воспоминания Л.Д. Клеймана (Муллера), члена Центросибири, участника событий лета 1918 г. в Кяхте и находившегося там до последних дней существования Троицкосавского Ревкома и Совдепа. Как пишет Е.М. Даревская, при личной встрече, состоявшейся 26 июля 1971 г., Л. Муллер сообщил, что А.И. Малафеев, которого считали пропавшим без вести, был убит при переходе из Монголии в Маньчжурию осенью 1918 г.

На самом деле судьба А. Малафеева сложилась по-другому. Перед самым занятием Кяхты белыми отрядами 2 сентября 1918 г., за несколько дней до этого, он вместе с Л. Муллером и К. Волком скрылся в монгольском приграничном Маймачене. В дальнейшем он вернулся в Россию и уехал к своему знакомому в Читу. Его жена с ребенком поселилась в тот момент на Байкале в поселке Танхой у своей сестры, а он, приехав туда, был выдан белым властям местным жителем, будучи узнанным, после получения на станции Селенга (ныне Кабанского района Бурятии), паспорта. Попав в Верхнеудинскую тюрьму в декабре 1918 г. и готовясь к суду, который состоялся, летом 1919 г., он дал несколько показаний, в которых достаточно подробно описал свою деятельность на посту комиссара финансов. Рассказал он и историю создания кяхтин- 
ских бон. В частности, касаясь событий лета 1918 г., он написал в рамках дачи своих показаний следующее.

«Самым выпуклым фактом в жизни Троицкосавска служит выпуск банковских разменных знаков бон. В конце июня 1918 г. в отделении Госбанка стал ощущаться острый недостаток разменных знаков. Причиной к этому служило общее для всех городов Сибири явление - недополучение (денежных) подкреплений из центра и для Троицкосавска еще одна особая причина-это близость его к монгольской границе способствовавшей утечке мелкой монеты за границу. Еще задолго до этого времени некоторые отделения банков выпускали, боны и их хватало, только для удовлетворения местных нужд. Как гарантия от подделок служила наклейка гербовых марок и печатей отделений банков.

Когда Троицкосавское отделение Госбанка стало перед необходимостью выпуска местных знаков, дабы не дать уйти за границу последней мелкой монете, то в местном Казначействе гербовых марок не оказалось. Тогда отделение банка сделало попытку получить марки из других городов и с этой целью были разосланы телеграммы по всем Казначействам и отделениям Госбанков, но марок нигде не оказалось, так как они были уже израсходованы. Отделению банка не оставалось ничего другого как выпустить их безо всяких наклеек. Далее оказалось, что согласно уставов, без каких-либо знаков выпускать их нельзя. Тогда Управляющий Отделением М. Шувалов предложил единственный выход, разрезать сороковки и двадцатки (керенки) и наклеить их на выпускаемые боны. Кроме этого снабдить их печатью отделения банка, порядковым номером и подписями Комиссара и Управляющего банка, мотивируя это тем, что это будет, безусловно, гарантия от подделок и отделение не нарушит эмиссионного права. Коллектив служащих (банка) утвердил это предложение и таким образом мы выпустили боны на сумму 65000 р. Материал по этому вопросу хранится в отделении банка» [1, ф. 1547, оп. 2, д. 3, л. 105].

Данный документ говорит о том, что, во-первых, острый недостаток денег стал ощущаться в Троицкосавске-Кяхте только в конце июня 1918 г. Во-вторых, по мнению А.И. Малафеева, основная причина дефицита мелкой монеты заключалась в утечке ее за границу в Монголию. Ну и наконец, третье, основным инициатором и разработчиком этого мероприятия был управляющий отделения Госбанка М.И. Шувалов.

Исследователь Д. Петин делает правильный вывод о коллегиальном принятии решения по выпуску бон, говоря при этом о невозможности сейчас установить инициатора этого решения [2, с. 61]. Однако, теперь мы можем точно определить истинного автора этой эмиссионной операции Кяхтинского банка. И действительно, на тот момент только М. Шувалову, опытному банковскому работнику, было под силу продумать эту достаточно оригинальную фринансовую операцию и решить проблему обеспечения мелкими деньгами население, хотя бы на некоторое время. 
Суть самого эмиссионного нововведения, на наш взгляд, заключалась в следующем.

Как уже упоминалось, и это тоже было дискуссионным вопросом, принятие решение о выпуске бон было сделано, и это уже сейчас доказано архивными документами, 19 июня 1918 г., а вступило оно в силу 20-го числа этого же месяца. Согласно актам комиссии, выпуски бон были проведены, 3, 6 и 16 июля 1918 г. В ее работе принимали участие комиссар финансов А.И. Малафеев, и.о. управляющего Кяхтинским отделением государственного банка В.И. Ермоленко, и.о. контроллера И.В. Дидковский, кассир А.Д. Бруевич, помощник кассира П.П. Обухов, делегат от отдела городского хозяйства Н.Ф. Смирнов, комиссар учетно-контрольного отдела А.Р. Павловский, представитель Кяхтинского казначейства Ф.М. Неделяев и член учетно-ссудного комитета С.М. Немчинов, который, правда, в дальнейшем не принимал участия в комиссии по проведению последней эмиссии 16 июля [1, ф. 222, оп. 2, д. 59, л. 3].

Что касается инфляционного эффекта, то никакого нарушения эмиссионного права Центрального банка произведено не было. Сумма нужная для изготовления бон в казначейских знаках Временного правительства (так называемые «керенки»), достоинством 20 и 40 р. была взята по чеку с текущего счета Троицкосавской Городской Управы. Билеты были разрезаны на четыре части и наклеены на изготовленные бланки, с печатью, на которых красовался царский двухглавый орел и стояли две подписи А. Малафеева и В. Ермоленко. После этой нехитрой операции на свет появились купюры в 5 и 10 р. Далее, изготовленные боны поступили в кассу через обратный взнос их на текущий счет той же Управы [1, ф. 222, оп. 2, д. 59, л. 18].

Общая сумма напечатанных денег составила 65000 р. 3 июля было напечатаны боны на 15000 р., 6 июля — 25000 р. и 16 июля - 25000 р. [1, ф. 222, оп. 2, д. 59, л. 8]. Боны выпускались для использования местным населением по номинальной стоимости в Забайкальском крае, но в действительности имели хождение в границах Троицкосавского и частично Верхнеудинского уезда и конечно в монгольском Маймачене.

После взятия Троицкосавска белыми отрядами, 25 ноября 1918 г. состоялось заседание еще одной комиссии в составе управляющего Кяхтинского отделения госбанка М.И. Шувалова, и.о. контролера В.И. Ермоленко, кассира А.Д. Бруевича и нового Городского головы А.А. Лушникова. Был вскрыт несгораемый ящик с неиспользованными бланками бон 5-ти рублевого достоинства в количестве 1022 шт. и 10-ти рублевого достоинства 4558 шт., которые были уничтожены [1, ф. 222, оп. 2, д. 59, л. 12].

Штемпель с подписью А. Малафеева был отдан в Городскую Управу, в дальнейшем он хранился в Кяхтинском краеведческом музее.

В феврале 1919 г. из Омска в Троицкосавск поступил циркуляр Колчаковского Центрального Управления Госбанка за № 20. В нем в частности говорилось следующее. 
В переживаемый ныне период расстройства во всех областях государственной жизни выпуски денежных знаков и их суррогатов производились не только в центре, но и на местах, свергнутой советской властью, образовавшимися после нее областными и краевыми правительствами, военными властями, частными банками, городскими самоуправлениями, правлениями фабрик и заводов и другими учреждениями.

Выпуски местных денег, без разрешения центральной власти и даже без осведомления Госбанка об этом, сильно затрудняют работу последнего, как регулятора денежного обращения в стране и отрицательно влияют на расстроенные и без того финансы страны.

В ввиду изложенного, признавая необходимым, в целях принятия мер к урегулированию денежного обращения, иметь точные сведения обо всех произведенных в районе Отделения выпусках местных денежных знаков, Госбанк предлагает вам донести, применительно к требованиям прилагаемой при сем фрормы, обо всех произведенных в районе Отделения выпусках местных денег с приложением копий указов, распоряжений и других актов о выпусках денег и образцов местных знаков в двух экземплярах.

«Вместе с сим, Госбанк подтверждает необходимость скорейшей рассылки теми Отделениями, коими производились выпуски местных денег во все Отделения образцов, выпущенных ими дензнаков, необходимых для сличения при размене местных денежных знаков на общегосударственные, согласно указаниям циркуляра от 14 декабря 1918 г. за № 32.

Управляющий Рошковский» [1, ф.. 222, оп. 2, д. 59, л. 16].

В ответ было отправлено сообщение следующего содержания.

«В центральное управление Госбанка.

Марта 25 числа 1919 г.

Исходящий № 812.

Во исполнение циркулярного предписания Госбанка от 18.02.1919 г. за № 20, Кяхтинское отделение, препровождая при сем ведомость о выпущенных Отделением местных денежных знаков, копии актов об их изготовлении их и образцы этих знаков в 2 экз., имеет честь донести, что выпуск их последовал по постановлению местного Совдепа от 19 июня 1918 г. в виду острой нужды в мелких денежных знаках и совершенной в то время оторванности от центра.

Выпущенные Отделением денежные знаки и в настоящее время не изъяты из обращения вследствие недостаточного количества мелких купюр, которыми была бы возможность заменить их» [1, фр. 222, оп. 2, д. 59, л. 17]. То есть местная и уже новая белая власть признала пользу этих денежных суррогатов, и не хотела их изымать из оборота, хотя предписания об этом получила из Читы уже в начале осени 1918 г. наверно потому, что заменить их было просто нечем.

В работах исследователей отмечается, что наибольший эффрект от использования этих денежных знаков наблюдался в течение двух месяцев, 
а затем после выпуска Центросибирью, летом 1918 г. своих денежных знаков стал сходить на нет. На наш взгляд, это является спорным утверждением, ведь известно, что новые советские деньги не были приняты главным фринансовым индикатором торговой жизни Кяхты - находящимся через границу торговым Маймаченом. «Малафеевки» же, по сути, тоже советские, но зато свои, местные, продолжали приниматься китайцами и монголами, которые хоть и осторожно поначалу, но в дальнейшем признали, эти в сущности денежные, но суррогаты, и доверяли им определенное время.

В заключении, вполне уместно задать вопрос: «Как же сложилась судьба этих денег в дальнейшем?».

В выходившей в Верхнеудинске газете, «Прибайкальская жизнь», уже далеко после установления власти атамана Семенова в Забайкалье, а именно 31 января 1919 г., в № 127, была опубликована заметка журналиста А.Г. Кузнецова с новостями из Троицкосавска. Вот, что он писал: «Город стал не город, а какое то, огромное кладбище. Прежний шумный базар превратился в пустыню. Магазины закрыты, заколочены. А мелкие лавочки стоят без окон и дверей и служат убежищем для бродячих собак.

Съестные припасы достаются с трудом. Цены на все по последней моде: фунт мяса - баранина - 2 р. 80 к., скотского - 1 р. 80 к., ветчины - 6-7 р., масла в продаже нет, фунт хлеба ржаного горьковатого 1 р., лучший сорт - 1 р. 30 к., пшеничного - 1 р. 80 к., полубелого - 2 р. 50 к. и белого - 4 р. Белой муки в продаже нет. Выдавали по карточкам с сентября месяца по 8 фунтов на человека, да и то не всем.

Политическая жизнь совсем замерла. В силу некоторых сложившихся обстоятельств, образовалась особая Троицкосавская республика...

Приезжающую публику город не балует. Для гостей имеются всего лишь «Центральные номера» Лушникова с платой по 15-ти р. в сутки за одни стены. Обед 7-8 р. из 2-х блюд, фрунт хлеба 4 р., самовар - 1 р. 50 к.

Весьма печально обстоит дело с денежными знаками. Совдепки в 50 р. и гербовые марки совершенно не принимаются. Купоны идут лучше. За то в качестве разменного знака употребляются в городе и окрестностях «Малафреевки». Это боны, выпущенные Кяхтинским Народным банком по образцу совдепок с маркой, но вместо марки наклеена четвертая часть «керенки». От двадцатки - в 5 р. и сороковки - в 10 р. С подписями комиссара Малафеева».

В дальнейшем по сообщению верхнеудинского коллекционера-бониста 30-х гг. прошлого столетия М.С. Сафонова, после ухода белых и установления власти Дальневосточной республики в 1920 г., отделение Государственного банка в Кяхте было расформировано и переведено в Верхнеудинск. Собранные боны были полностью сожжены в печах Верхнеудинского винного склада вместе с прочими аннулированными кредитными билетами ревизующей комиссией Центрального Управления Государственного банка и ныне являются большой редкостью [3, с. 171]. 
В историографии изучаемой нами проблемы есть еще одна деталь, которая носит дискуссионный характер. В указанной выше статье Д. Петин пишет, что в работах, посвященных этому событию, встречаются искажения при написании фрамилии уездного комиссара фринансов и утверждает, что вариант написания (Малофеев), через букву «O» во втором слоге является правильным, так как выявлен в ходе анализа делопроизводственных источников Центрального управления Государственного банка Министерства финансов правительства А.В. Колчака [2, с. 61]. Но в результате изучения следственного дела комиссара А. Малафеева выясняется, что правильное написание фрамилии все-таки Малафеев. Подтверждением этому служат оригинальные подписи под своими показаниями белогвардейскому следователю и самое главное - сохранившийся в отличном состоянии паспорт, выданный ему в декабре 1919 г., где указаны также рост, цвет волос и прочее [1, ф. 1547, оп. 2, д. 3, л. 121].

26 мая 1919 г. в Верхнеудинске закончились заседания прифронтового военно-полевого суда, который поначалу вынес смертный приговор, но затем после апелляции и положительного отзыва атамана Г. Семенова, приговорил бывшего комиссара финансов к 4 годам каторги низшей степени и лишению всех прав состояния [1, фр. 1547, оп. 2, д. 3, л. 91, 92]. Дальнейшая судьба А.И. Малафеева неизвестна. Он действительно пропал без вести, но денежные купюры с его фамилией еще долго ходили по рукам населения в Троицкосавском уезде, напоминая о тяжелых годах экономической разрухи.

В целом, кяхтинские боны выполнили свою историческую миссию по облегчению экономического положения населения Кяхты и послужили интересным и поучительным примером для будущих финансовых властей очень выверенной и эффрективной фрормулой своего приложения. Ну, а в истории славного города Кяхты появилась еще одна страничка появление своих собственных денег в трагические и судьбоносные годы революции и гражданской войны.

\section{Список использованной литературы и источников}

1. Национальный архив Республики Бурятия. - Ф. 222, 1547.

2. Петин Д. И. Эмиссия денежных суррогатов советской властью в Кяхте летом 1918 года / Д. И. Петин // Вестник Томского Государственного Университета. История. - 2017. — № 47. - С. 59-64.

3. Погребецкий А. И. Денежное обращение и денежные знаки Дальнего Востока за период Войны и Революции (1914-1924) / А. И. Погребецкий. - Харбин : Изд-во Об-ва изучения Маньчжурского края и Дальневосточно-Сибирского об-ва «Книжное Дело», 1924. - 429 с.

4. Сафонов М. С. Бонные эмиссии Прибайкалья 1918 года / М. С. Сафонов // Советский коллекционер. - 1930. - № 7. - С. 169-172. 


\section{Информация об авторе}

Кургузов Павел Владимирович - соискатель кафедры философии, истории и культурологии, Восточно-Сибирский государственный университет технологий и управления, 670013, г. Улан-Удэ, ул. Ключевская, 40B, стр. 1; e-mail: bpnf1968@bk.ru

\section{Author}

Pavel V. Kurguzov - PhD student, Department of Philosophy, History and Cultural Studies of the East Siberia State University of Technology and Management, 40B bld 1 Klyuchevskaya St., 670013, Ulan-Ude, Russia; e-mail: bpnf1968@bk.ru 